\title{
Use of administrative hospital registry data and a civil registry to measure survival and other outcomes after cancer
}

This article was published in the following Dove Press journal:

Clinical Epidemiology

19 July 2011

Number of times this article has been viewed

\author{
Henrik Toft Sørensen \\ Timothy L Lash \\ Department of Clinical Epidemiology, \\ Aarhus University Hospital, \\ DK-8000 Aarhus, Denmark
}

For many decades, cancer registries have been a cornerstone in monitoring cancer occurrence in different populations. Cancer registries in the Nordic countries are characterized by a high level of completeness and excellent data quality. ${ }^{1}$ Cancer diagnoses are often validated through several procedures, with documentation of clinical evidence for the diagnosis. Cancer registries have proven very useful in monitoring cancer incidence, contributing significantly to our understanding of its origin and development. Some registries also have been used to monitor cancer survival at the population level. ${ }^{1}$

Since the early 1990s there has been an increasing demand to measure the performance of health care systems in treating a number of diseases, including cancer. "Outcomes" refers to the results of the health care delivery process. ${ }^{3}$ For cancer treatments, the main outcomes are: 1) clinical status, including survival; 2) functional status; and 3) consumer satisfaction. Five-year overall survival has long constituted the main clinical outcome in cancer research. ${ }^{2}$

The aim of any system designed to monitor the performance of a health care system is to help clinicians and health care administrators detect suboptimal clinical practices and to guide clinical decisions and policy, with the overall goal of achieving measurable improvements in health care. ${ }^{3}$ An effective monitoring system must fulfill the following requirements: ${ }^{4}$

1. Data must be continuously updated.

2. Data must be complete and of adequate quality.

3. Data must be accessible on a regional level, and preferably also on a hospital level.

4. Data must contain relevant clinical endpoints.

5. Data must be collected continuously in clinical practice.

Cancer registries often are limited in these respects. One problem is lag time in data delivery (in some cases several years). Another is that information on treatment is restricted to that available at the time of diagnosis. As well, some registries do not provide linkage to mortality data. Finally, data collected by cancer registries are not routinely returned to clinical departments, limiting the feedback received by the specific health care delivery points. Many cancer registries thus provide only an incomplete view of the clinical course of cancers.

In this Supplement to Clinical Epidemiology, current survival data after cancer treatment in Denmark are reported on a regional level. The analyses were based on administrative hospital registry data linked to a civil registry, both of which are available
Correspondence: Henrik Toft Sørensen Department of Clinical Epidemiology, Aarhus University Hospital, Olof Palmes Allé 43-45, DK-8200 Aarhus N, Denmark Tel +4589424827

Fax+458942 480I

Email hts@dce.au.dk
Clinical Epidemiology 20 I I:3 (Suppl I) I-2

(C) 20II Sørensen and Lash, publisher and licensee Dove Medical Press Ltd.This is an Open Access article which permits unrestricted noncommercial use, provided the original work is properly cited.
Dovepress

http://dx.doi.org// 0.2147/CLEP.S22509 
in many countries, but much underutilized for the purpose of performance monitoring. The papers show improvements in prognosis for some cancers and less convincing results for others. Of note, the analyses were conducted in close collaboration among clinicians, epidemiologists, and statisticians. Only a limited portion of available data was used in the papers presented here.

Hospital registries provide relevant, current, continuous, and complete patient data, including type of admission (acute/ elective), type of surgery, baseline and acquired comorbidities, ${ }^{5}$ and certain complications such as deep venous thrombosis. ${ }^{6}$ A significant portion of these data are of high quality. Other data are underutilized, and their quality and completeness remain unknown (eg, information on nonsurgical treatments, including chemotherapy and radiation therapy, and complications such as infections). The quality of data on such variables must be ascertained before they are used for health care quality monitoring. Another issue is that the ICD-10 (International Classification of Diseases, 10th Revision) coding often used in hospital registries lacks information on cancer stage. While this is a limitation for some analyses, earlier average stage diagnosis over time may itself indicate improved performance of the health care system, so adjustment of survival rates for changes in stage at diagnosis would actually mask improvements of some aspects of health care delivery.

A number of outcome measures found in hospital registries are very relevant for monitoring treatment quality. These include postoperative mortality, ${ }^{7}$ repeat operations, duration of hospitalization, admission to an intensive care unit, ${ }^{8}$ use of blood transfusions, ${ }^{9}$ surgical complications such as lung embolism, readmissions for infection, and later occurrence of metastases. ${ }^{10}$ Thus, in contrast with cancer registries, hospital registries have the potential to provide longitudinal data on the clinical course of cancer patients, including the occurrence of cancer-related late effects of treatment or the cancer itself. ${ }^{11}$

How can such data be used in clinical practice? A good starting point is to compare one's own clinical practice with best practices in evidence-based medicine. ${ }^{12}$ Defined guidelines are available for a number of diseases. If a gap is identi- fied, its extent and the underlying reasons must be determined, possibly through audit. Clinicians can then develop tools to close this gap and examine their success through new analyses. The present papers result from such a feedback system, showing the feasibility of a multidisciplinary approach and the potential to identify shortcomings in performance that, if corrected, would improve the survival and quality of life of cancer patients.

\section{References}

1. Storm HH, Michelsen EV, Clemmensen IH, Pihl J. The Danish Cancer Registry - history, content. Dan Med Bull. 1997;44:535-539.

2. Hewitt M, Simone JV. Ensuring Quality Cancer Care. Washington DC: National Academy Press; 1999.

3. Nolan TW. System changes to improve patient safety. BMJ. 2000;320: 771-773.

4. Gunnarsson U. Quality assurance in surgical oncology. Colorectal cancer as an example. Eur J Surg Oncol. 2003;29:89-94.

5. Cronin-Fenton DP, Nørgaard M, Jacobsen J, et al. Comorbidity and survival of Danish breast cancer patients from 1995 to 2005. Br J Cancer. 2007;96:1462-1468.

6. Pedersen AB, Sorensen HT, Mehnert F, Overgaard S, Johnsen SP. Risk factors for venous thromboembolism in patients undergoing total hip replacement and receiving routine thromboprophylaxis. $J$ Bone Joint Surg Am. 2010;92:2156-2164.

7. Hansen JB, Thulstrup AM, Vilstup H, Sørensen HT. Danish nationwide cohort study of postoperative death in patients with liver cirrhosis undergoing hernia repair. Br J Surg. 2002;89:805-806.

8. Christensen S, Johansen MB, Tønnesen E, et al. Preadmission betablocker use and 30-day mortality among patients in intensive care: a cohort study. Crit Care. 2011;15:R87.

9. Yong M, Riis AH, Fryzek JP, Møller BK, Johnsen SP. Predictors and patterns of red blood cell transfusion use among newly diagnosed cancer patients with chemotherapy-associated anemia in Western Denmark (1998-2003). Clin Epidemiol. 2011;3:91-99.

10. Nørgaard M, Jensen AØ, Jacobsen JB, Cetin K, Fryzek JP, Sørensen HT. Skeletal related events, bone metastasis and survival of prostate cancer: a population based cohort study in Denmark (1999 to 2007). J Urol. 2010;184:162-167.

11. Rowland JH, Hewitt M, Ganz PA. Cancer survivorship: a new challenge in delivering quality cancer care. J Clin Oncol. 2006;24:5101-5104.

12. Bero LA, Grilli R, Grimshaw JM, Harvey E, Oxman AD, Thomson MA. Closing the gap between research and practice: an overview of systematic reviews of interventions to promote the implementation of research findings. The Cochrane Effective Practice and Organization of Care Review Group. BMJ. 1998;317:465-468.
Clinical Epidemiology

\section{Publish your work in this journal}

Clinical Epidemiology is an international, peer-reviewed, open access journal focusing on disease and drug epidemiology, identification of risk factors and screening procedures to develop optimal preventative initiatives and programs. Specific topics include: diagnosis, prognosis, treatment, screening, prevention, risk factor modification, systematic reviews, risk \& safety of medical interventions, epidemiology \& biostatical methods, evaluation of guidelines, translational medicine, health policies \& economic evaluations. The manuscript management system is completely online and includes a very quick and fair peer-review system, which is all easy to use. 